\title{
Teaching EFL Reading Skills with Instructional Scaffolding Microlectures: Chinese Non-English Major Undergraduates' Performances and Perceptions
}

\author{
Lisha Liu \\ Southern University of Science and Technology, \\ Shenzhen, China
}

\begin{abstract}
Teacher - centred lecturing, the dominated teaching style at Chinese universities is facing enormous challenges as microlectures prevail in higher education pedagogy nowadays. Some Chinese lecturers have begun exploring how to use microlectures in their own programmes in order to improve their teaching performances and students' learning outcome. However, currently, the teaching practice of using microlectures in college English classes seems to be still at a trial stage, which creates much space for our further investigation into its teaching effects. This paper describes a study conducted at Southern University of Science and Technology, which seeks to explore non-English major undergraduates' performances through and perceptions of teaching English reading skills with instructional scaffolding microlectures. After an analysis of 34 1st-year undergraduates' standardized reading tests, self-evaluation sheets of reading skills and reading course feedback self-reports, the findings show that this teaching method can improve students' English language proficiency, learning interest and independence effectively.
\end{abstract}

Keywords: microlectures, English teaching, student feedback, scaffolding

RESEARCH BACKGROUND

Computer-assisted language learning (CALL) was introduced to the English classes at Chinese universities in 2002 (Chen, Wang \& Jiang, 2015), aiming to help non-English major undergraduates improve their English learning efficiency. However, during these years, it appears that this teaching model is not as promising as our expectations and has little effect on raising students' learning efficiency. This is because it mainly focuses on pre- or after-class selflearning via the online English learning platforms established by universities. Without constant and appropriate supervision and instruction from teachers, students often show a lower level of self-discipline and find it difficult to devise an individualized learning plan after class. As a result, they usually achieve unsatisfactory learning outcomes. In order to solve this problem, an increasing number of college and university English lecturers attempt to develop and employ diverse information technology-aided teaching instruments to grasp students' learning progress and outcome in a more efficient way.

\section{LITERATURE REVIEW}

In terms of teaching English reading, teacher-centred intensive reading is a popular teaching method at Chinese colleges and universities presently. Although there are various teaching materials for college English reading courses, the given teaching objectives remain unclear. This is because some vague expressions like "understanding the text" or "grasping the language points in the text" are universally applicable. They may drive English lecturers to excessively emphasize the analysis of the language points, rather than cultivate students' practical reading ability. There are also texts involving reading strategies and techniques. Yet, 
since they are not regarded as key teaching points, lecturers usually leave them out of consideration and spend little time on the relevant contents. Consequently, students find it difficult to understand these strategies profoundly, let alone improving their reading skills by applying these strategies to practical English reading scenarios. Through long-term teaching observation, some lecturers found that the intensive reading method could neither help nonEnglish major undergraduates understand their subject articles written in English, nor improve their abilities to grasp or predict the general ideas of these articles (Liu, 2014). Similarly, based on several years' research, Professor Cai (2012) pointed out that non-English major undergraduates, trained through intensive reading, were likely to form a habit of reading slowly and depend on teachers and dictionaries when reading. These drawbacks seem to be acceptable in high school when they are supposed to focus on the learning of language points. However, they have severely run counter to the purpose of college English reading that aims at developing reading skills. Under this circumstance, it is of great importance to teach students reading strategies and skills in order to accelerate their reading and deepen their comprehension.

Among the information technology-aided teaching instruments, microlecture is not only a type of visual multimedia resources, but also serves as an application in student-centred classes. According to Educause, a professional non-profit association that helps higher education optimize the impact of information technology, a microlecture means "a short recorded audio or video presentation on a single, tightly defined topic that supports online, blended or face-toface learning" (2012). The Higher Education Institutions Teacher Online Training Centre of the Ministry of Education in China defines the microlecture as "a compact and complete teaching activity held by a teacher regarding a specific knowledge point or teaching process in the form of a recorded video"(2014). The definitions suggest that the microlecture is, in fact, a type of visual multimedia learning resource that contains a limited amount of information. It has demanding design requirements and integrates different teaching processes with regard to the presentation on knowledge points. For lecturers, it is a teaching information carrier that can be applied to classes as part of the presentation. Compared with common video resources, it is more systematic and directed for the integration of the teaching processes concerning language knowledge and skills with a relatively small information capacity. For students, microlectures better meet their demands for diversified and individualized learning and thus they are efficient in helping students learn English knowledge and skills. Additionally, as a constituent of a course, microlectures can address the development of English reading strategies and the improvement in English reading skills.

Through extensive reading and analysis of the relevant literature, I found that many educational scholars and teachers viewed that the application of microlectures was mainly in flipped classes. In other words, students should watch the microlectures of knowledge presentation before class and complete micro-exercises to obtain profounder understandings of the corresponding knowledge after class. This is because it is difficult to give full play to the microlectures in class which lasts less than an hour. In consequence, they remain dependent on the presentation of teachers or communication and discussion with classmates. However, I held the opposite idea. Teachers cannot ensure whether their students have participated in microlectures before or after class. On the contrary, it seems to be easier and more convenient for a teacher to manage students' learning when they are staying together in class. In class, microlectures can be applied to the teaching processes in different ways to increase students' engagement and improve their English by changing the passive learning pattern in the traditional teaching scenarios. Therefore, further study should be carried out to probe into the effect of applying microlectures of English reading skills to college English reading classes. 
In addition to teaching contents, teaching methods are also important in microlectures. Among all student-centred teaching methods, scaffolding is able to change the passive learning pattern of students in the traditional teaching scenarios. It is tailored to students' needs with the intention of increasing their learning engagement and improving their English language skills (Kirschner, 1992). If scaffolding can be embedded in microlectures, it may drive students to make use of the scenarios and materials provided by teachers and discover the corresponding English skills through proactive thinking and independent exploration. In terms of the reading course, with the microlectures as the instructional scaffolding teaching instruments, the reading skill teaching can change the pattern of listing language points and overcome the disadvantage of unclear teaching objectives. In this case, teaching English as a foreign language (EFL) reading skills with instructional scaffolding microlectures is practical and valuable for further research.

\section{RESEARCH METHODS}

The purpose of this study is to explore Chinese non-English major undergraduates' performances through and perceptions of teaching EFL reading skills with instructional scaffolding microlectures. A mixed-method approach was used to investigate students' reading test results and feedback on the teaching effect. This is because it was likely to produce better results to achieve my research goal and could improve the research validity and reliability from a pragmatic perspective (Morgan, 2007).

The empirical investigation was conducted at Southern University of Science and Technology. There were approximately 608 1st-year non-English major undergraduates. Through convenient sampling, 34 participants in a class voluntarily participated in this study. Their placement test results show that they were all intermediate learners in EFL reading. The reading skill microlectures which were used in class were created by me and composed of five segments: skimming, scanning, word meaning in context, critical reading and predictive inference. Among these skills, the first three are basic reading skills and the last two are regarded as advanced reading skills. These microlectures were designed with conceptualised questions, mini-votes and exercises for students' inductive learning. At the same time, the interactive response system (IRS), an important facility aiming at improving the teaching quality, was used in class, which could efficiently collect students' feedback to the teachers.

The data collection and analysis of this study involved both quantitative and qualitative data, but dominated by the qualitative element. The quantitative part was to analyse the scores of students' English standardized reading tests and their self-evaluation scores in each reading skill through descriptive statistics. Firstly, I employed the reading test in MELAB (Michigan English Language Assessment Battery) for the students of this grade to do the reading test before and after my teaching. Subsequently, they were divided them into different groups from B1 to $\mathrm{C} 1$ according to the Common European Framework of Reference for Languages (CEFR) criteria. Secondly, I made students answer questions about how they feel before and after class in written form by using a self-evaluation sheet of reading skills. Likert scale $(1-$ the lowest level, 5 - the highest level) was adopted to know students' self-evaluation about what they had learned on reading skills by this teaching method.

As for the qualitative part, a student's written feedback self-report was adopted because it provided a better access to the participants' different inner perceptions, attitudes and feelings of their learning experiences related to this teaching method. In addition, it would not inhibit participants' responses. At the beginning of data analysis, pages of text data from five participants' self-reports were processed through line-by-line open coding with reflection memos. Based on this initial coding, some specific segments of information emerged from the 
texts and grouped together for continuous coding of the other 29 self-reports. During the continuous coding process, the coded texts were re-coded if they seemed to be inappropriate. In order to establish the trustworthiness of the qualitative data analysis, member checking from the participants and peer debriefing from two experienced qualitative researchers were adopted. Finally, four main themes were extracted from the data, which organised the research findings.

\section{Students' Performances}

\section{RESEARCH FINDINGS}

The quantitative part aims at evaluating whether this teaching method is helpful to students' English reading teaching by analysing their performances on standardised reading tests. In terms of the reading test scores, based on the pre-course MELAB reading test results and the CEFR criteria, 6 participants reached the B2 level (independent user), accounting for 18\% of the total number. It means that they were able to read and understand English articles in familiar topics. After a semester's learning through instructional scaffolding microlectures, students then took the MELAB reading test of an equivalent level of difficulty, and it turned out 11 students reached the B2 level, accounting for 32\% of the total number. An increase of 14 percentage points indicates that this teaching model may have some effects on promoting the reading ability of students.

From 34 student participants' self-evaluation scores on their English reading skills, it can be seen that most of them thought their English reading capacity improved. Table 1 shows the results.

Table 1 Students' self-evaluation average scores

\begin{tabular}{|l|c|c|}
\hline Reading skills & $\begin{array}{l}\text { Average scores of pre- } \\
\text { course evaluation }\end{array}$ & $\begin{array}{l}\text { Average scores of post- } \\
\text { course evaluation }\end{array}$ \\
\hline Skimming & 3.24 & 3.77 \\
\hline Scanning & 3.12 & 3.52 \\
\hline $\begin{array}{l}\text { Word meaning in } \\
\text { context }\end{array}$ & 3.07 & 3.42 \\
\hline Critical reading & 2.94 & 3.52 \\
\hline $\begin{array}{l}\text { Predictive } \\
\text { inference }\end{array}$ & 2.71 & 3.13 \\
\hline
\end{tabular}

With regard to the basic reading skills, the pre-course average scores of skimming, scanning and word meaning in context are 3.24, 3.12 and 3.07, but the post-course scores are 3.77, 3.52 and 3.42. In addition, the students who marked post-course self-evaluation scores 4 to 5 account for $61.29 \%, 51.56 \%$ and $38.71 \%$ of the total number. These indicate that all ratios increase compared with the scores before my course. The above shows that students believed their three basic reading skills improved by adopting this teaching method. The progress is even more significant in advanced reading skills, the pre-course average scores of critical reading and predictive inference are 2.94 and 2.71 while the post-course scores are 3.52 and 3.13, increased by $19.72 \%$ and $15.50 \%$ respectively. The students who marked post-course self-evaluation scores 4 to 5 account for $57.71 \%$ and $41.93 \%$, both are higher compared with the pre-course scores. The above data indicates the instructional scaffolding microlectures of English reading skills may contribute to the training of students' critical reading and the predictive inference. 


\section{Students' perceptions}

According to participants' self-reports, their feedbacks on the teaching effect were mainly summarised by four themes: English proficiency, learning interest, independent learning, and teaching evaluation.

\section{English proficiency}

Prior to my reading course, in terms of English proficiency, especially in reading, most participants mentioned that insufficient vocabulary and lack of thinking in English were the major obstacles. Participant No. 12 attributed slow reading to a limited range of vocabulary while participant No. 10 blamed most of all on the lack of an English mind.

"My English vocabulary is limited and I don't understand many words' meanings. I usually forget their meanings within a couple of minutes. Moreover, I have to see new words at least three times in an article before I'm able to get a sense of them in the sentences. This is rather disheartening. I might just be unable to grasp the meaning of a sentence even if I know every word in it. I read very slowly".

"...Unable to think logically as the way native speakers do, I met with some sentence patterns that puzzled me for a long time."

In contrast, after taught by this teaching method, 31 participants gave quite different comments on their English reading ability. For example, participants No. 6 and No. 10 believed,

"Now I possess the ability to guess the meanings of some words, I see some improvement in my generalization ability, and I find myself able to guess what's coming next in the text ... I, as a minimum, have made some substantial progress in reading speed that I'm now able to finish reading an article within 10 minutes."

"I've got some reading techniques, and I've got some insight into some foreign cultures, too. I learned some skills that helped me recognize the techniques employed by the writer ... my vocabulary has grown appreciably, and I can do better in analysing sentence patterns. Now I read faster and have a deeper understanding of the contents..."

In addition to English reading ability, some participants were convinced that this teaching method was beneficial to other aspects of English proficiency as well. Participants No. 11 and No. 28 said that they had made improvements in both oral communication skills and writing skills.

"Having gained some reading skills in class, I read more and faster, and accordingly I may build up my reserve of English words and expressions, which enable me to make better use of my knowledge. To say the least, I'm better in oral communication than before."

"Learning is always rewarding. I guess the writers' writing purposes, and I put some similar purposes into my own writing, and I find my writing reads more fluently."

Participants' comments suggest that reading skill microlectures interwoven with scaffolding instructions benefit them not just some reading strategies and skills. More than that, they became more effective in building up vocabulary, speeding up their reading, and increasing their knowledge. This shows the effectiveness of this teaching method in improving students' English reading. Meanwhile, it is also beneficial to the capability of using English in other ways. The benefits are multiple. 


\section{Learning interest}

Most participants agreed that the reading skill microlectures created by me were beneficial. Teaching them with these instructional scaffolding microlectures in class aroused their interest in learning English. Participants No. 8 and No. 24 declared that these resources provided a systematic way of developing reading ability and were helpful in their learning. They became thus more interested.

"English reading is a skill that is both important and necessary. When I was studying at high school, this skill received no systematic treatment. Luckily, the microlectures taught me systematically about how to employ these skills by framing them in my mind. This is compatible with my understanding. So, learning becomes interesting."

"I think this type of teaching is creative, and accordingly it is easier to locate points of interest. In each microlecture, I get some reading skills, which are systematic enough and helpful in improving my reading capacity."

Participant No. 17 said that the instructional scaffolding microlectures benefited him greatly and thanks to it he had made remarkable progress in English reading. Participant No. 7 believed these microlectures met his needs for certain English reading skills. All these show that such microlectures do help students expand their reading knowledge, train their thinking ability, and arouse their interest in learning.

"Every microlecture is presented in an interesting and vivid manner, and it introduces some additional knowledge. In the beginning, I didn't have much interest in English reading, but this way of lecturing is very attractive. It not only trains our logical ability, but expands our knowledge as well."

"(We) have a lot of subject books written in English, so reading is a must. But, reading at your free will is not systematic or regular enough. Fortunately, such microlectures provide me with a systematic and regular way. Short videos and micro-exercises made me more impressed with these skills. And I can watch them again, if I like..."

All the above statements suggest that English reading skill instructional scaffolding microlectures not only train students' reading in a more efficient and systematic way, which leave them with a deeper impression, but also expand students' knowledge and develop their thinking. Therefore, this practice does produce some effect in meeting students' learning needs and enhancing their interest in learning.

\section{Independent learning}

In participants' self-reports, they gave a consistent comment on whether instructional scaffolding microlectures of reading skills have any effect on their independent English learning. The comment was that this teaching method indeed raised their awareness of the importance of autonomy in college English learning.

"An English reading microlecture is short in time, but in screen, the teacher instructs us, more often than not, to be explorative in reading skill development and doing exercises. The purpose is to let us know that autonomous learning is necessary in college English learning and, in order to have a more profound understanding of a certain reading skill, much autonomous learning is necessary."

"... in such a classroom, can you 'survive' pretty well without taking initiative and being autonomous in learning? (laughter)" 
Among all the participants, 23 admitted that such a teaching method enabled them to make progress of varying degrees in English learning ability. Then, they knew how to be initiative in tackling problems and how to find English reading learning materials.

"... (Independent learning ability) can be said to have been improved, because now I'm in the habit of compelling myself to think more in class; otherwise I won't be able to answer the questions the teacher asks in microlectures. Also, when class is over I'll press myself to read some English."

"I believe I've made some solid progress in autonomous and independent learning. The microlectures taught me some reading skills, and now I make it a habit of reading some English newspaper or websites.

All these statements show that embedding instructional scaffolding microlectures of reading skills into college English class plays a role in cultivating students' autonomous learning ability from both cognitive and behavioural aspects.

\section{Teaching evaluation}

I asked the participants to write down what they think of this practice in their feedback selfreports. 30 participants said they were satisfied with it. Some of them believed that the incorporation of microlectures could make clearer the objectives of reading skill development and highlight difficult points.

"I am very pleased with this teaching method. One reading skill is taught in each class, the objectives of learning are well defined, and some class exercises are provided. The efficiency is pretty high."

"This (teaching) method is very good. The difficult and key points are clearly explained and also presented in a straightforward way. Once you gain some reading skills, you may overcome the problem of unknown words, slow reading speed, and similar difficulties."

Other participants stated that I was innovative by combining scaffolding with microlectures. Planting conceptual questions in a reverse order in class and presenting the knowledge in the particular way enabled them to have a better understanding of reading skills and become more proficient in using these skills.

"... in the videos, some questions were firstly posed by the teacher, making us to review our methods of reading. Our answers were fed back to her through a responder. This made me realize that I had indeed used some reading skills without knowing them. Now, video learning streamlined our skills and gave us a clear thinking."

"This was the first time I had an experience with this reverse order of lecturing. It's quite novel. So, we would watch the videos with more interest and attention. We took notes and did exercises too. We have done so much more, and we become better at what is expected of us. This way of teaching is far better than pure lecturing, the latter making it so easy to forget what's been lectured... "

From the perspective of teaching evaluation, many participants were quite appreciative of this teaching method. Because it not only gives clear learning objectives for each reading class, but also minimizes students' "pseudo-understanding" of reading skills. It promotes learning engagement and depth. 


\section{DISCUSSION AND CONCLUSION}

Although the number of samples in this study is limited, from the view of the quantitative and qualitative analysis of this study, the teaching model which combines microlectures of English reading skills with scaffolding does benefit the college English reading teaching. It can effectively improve their English proficiency and develop their learning autonomy.

First, the standard language test suggests that this teaching method is useful to improve students' reading test scores. The self-evaluation scores before and after my course demonstrates this teaching model is also advantageous to improve students' basic and advanced reading ability.

Second, creating reading skill microlectures can enrich the digital resources of college English teaching. Its organization is more systematic than traditional lecturing. It is easier for students to form and idea of "how to read", which can benefit their reading effectiveness. Moreover, microlectures can expand students' knowledge. This can well meet the students' subject needs while they are learning through English.

Third, inserting microlectures with inductive scaffolding of teaching can avoid the problems such as listing key points only and unclear teaching objectives. It can not only facilitate students to grasp the main points of reading skills through micro surveys and exercises, but also enhance teachers' quality of teaching.

Fourth, this teaching method can increase the interactions between students and teachers, which develops students' English learning initiative and independence. Meanwhile, creating microlectures which is student-centred can prompt students' personalized learning.

In conclusion, the teaching method is worth trying in teaching EFL reading at the university level. It can enable students to master corresponding reading skills more systematically to meet students' demand of using English in their own subject fields. It can also drive current college English reading teaching to be more goal-oriented and targeted, therefore to meet the practical need of college English study.

\section{References}

Cai, J. (2012), A Way Out for EFL at Tertiary Level Education in Mainland China. Shanghai: Shanghai Jiao Tong University Press.

Chen, Z, Wang, Y \& Jiang, J (2015), 'Problems and Solutions for the Contemporary Development of Microlectures', Modern Educational Technology, 10: pp. 67.

Educause (2012), 7 Things You Should Know about Microlectures. 11: pp.1.

Kirschner, P. (1992), 'Epistemology, Practical Work and Academic Skills in Science Education'. Science and Education, 1: pp. 273 - 299.

Liu, L. (2014), 'A Preliminary Discussion on Skill-based Reading Class Design in College English Teaching', Time Education, 3; pp. 115.

Morgan, D. (2007), 'Paradigms Lost and Pragmatism Regained: Methodological implications of combining qualitative and quantitative methods'. Journal of Mixed Methods Research, 1: pp.48 - 76.

The Higher Education Institutions Teacher Online Training Centre of the Ministry of Education (2014), Report on Microlecture Research at Chinese Universities. Retrieved from: http://weike.enetedu.com/report/. 